\title{
PHYSICAL AND MECHANICAL CHARACTERIZATION OF A POROUS CEMENT FOR METAPHYSEAL BONE REPAIR
}

\author{
Bruno Cimatti ${ }^{1}$, Edgard Eduard Engel ${ }^{1}$, Marcello Henrique Nogueira-Barbosa ${ }^{2}$, Paulo Donato Frighetto ${ }^{3}$, José Batista Volpon ${ }^{1}$
}

\section{ABSTRACT}

Objective: Macroporous cement with mechanical properties similar to cancellous bone may improve the treatment of large bone defects in relation to solid acrylic cement. The aim of this study was to compare physical and mechanical characteristics of a polymethyl methacrylate (PMMA) based porous cement with cancellous bone. Methods: Compressive strength and pore size, interconnectivity, and distribution of cylindrical porous PMMA cement samples containing 10\% (G1), $20 \%$ (G2) or 30\% (G3) effervescent components were analyzed. Results were compared to bovine cancellous bone (G4) and solid PMMA (G5) samples. Results: Scanning electron microscopy (SEM) of all experimental samples (G1 - G3) revealed a random distribution and a wide size variation of pores ranging from $50 \mu \mathrm{m}$ to $3 \mathrm{~mm}$. Micro-CT showed that G2 have high porosity and lower interconnectivity of pores. No significant differences in yield strength and Young's modulus were observed among G1, G2 and G3. G4 samples were slightly stronger and less elastic than the other groups. Solid PMMA is extremely strong and inelastic. Conclusions: PMMA based porous cement met the expected characteristics. High porosity with large and interconnected pores may allow for bone ingrowth. Strength and elasticity similar to cancellous bone may enhance mechanical stimuli to bone remodeling. Observational Descriptive Study.

Keywords: Polymethyl methacrylate. Bone transplantation. Bone neoplasms. Bone substitutes.

Citation: Cimatti B, Engel EE, Nogueira-Barbosa MH, Frighett PD, Volpon JB. Physical and mechanical characterization of a porous cement for metaphyseal bone repair. Acta Ortop Bras. [online]. 2015;23(4):197-201. Available from URL: http://www.scielo.br/aob.

\section{INTRODUCTION}

The curettage of benign bone tumors produce large defects that are at risk of fracture. They are often filled with solid blocks of polymethylmethacrylate (PMMA). Other bone substitutes in different cement presentations do not provide immediate mechanical stability and their ability to remodel is not well established in the literature. ${ }^{1}$ Solid PMMA blocks allow immediate load support, but are related to complications such as bone and cartilage necrosis leading to arthrosis, when implanted in the periarticular subchondral region. ${ }^{2}$ The high temperatures reached during cement drying, the decrease in blood supply due to the confinement of the subchondral bone between the articular cartilage and the cement and the elasticity discrepancy between bone and cement are considered causes of the appearance of a radiolucent region around the block and eventually, its failure. ${ }^{1,3}$

Porous cements can be seen as reasonable alternatives to solid cement and many options based on PMMA ${ }^{4,5}$ and calcium phosphate $(\mathrm{CPC})^{6}$ have been reported. In addition to the recognized characteristics which are important for this purpose (for example, early mechanical strength and its unlimited availability), there are specific features that can be enhanced regarding solid cement, such as free diffusion of growth factors and other osteoinductive substances interconnected through pores ${ }^{7}$ and reducing the difference between the modulus of elasticity of cancellous bone and the cement. ${ }^{8} \mathrm{It}$ is believed that macropores favor bone intrusion. ${ }^{9}$ Many pore-forming techniques have been reported, especially for use in tissue engineering. ${ }^{10}$ However, only two of these techniques allow intraoperative modeling of the block, allowing perfect adaptation to the defect: a mixture of immiscible absorbable or soluble substances ${ }^{4}$ and adding of effervescent components. ${ }^{11}$

There is a natural tendency to fill bone defects triggered by mechanical stimuli. ${ }^{12}$ Hirn et al. ${ }^{13}$ stated that bone defects smaller than $60 \mathrm{~mm}^{3}$ do not require filling with bone substitutes because they remodel with a low risk of fracture $(5 \%)$, while larger defects require stabilization due to increased risk of fracture (17\%). However, almost all evaluated bone defects remodeled without any graft filling or other substitute.

All the authors declare that there is no potential conflict of interest referring to this article.

1. Universidade de São Paulo, Faculdade de Medicina de Ribeirão Preto, Department of Biomechanics, Medicine and Rehabilitation of the Locomotor System, Laboratory of Bioengineering, Ribeirão Preto, SP, Brazil.

2. Universidade de São Paulo Faculdade de Medicina de Ribeirão Preto, Division of Radiology and Diagnostic Imaging, Ribeirão Preto, SP, Brazil.

3. Instituto Federal de Educação, Ciência e Tecnologia, Campus Catanduva, SP, Brazil.

Work developed at Faculdade de Medicina de Ribeirão Preto da Universidade de São Paulo, Laboratory of Bioengineering, Department of Biomechanics, Medicine and Rehabilitation of the Locomotor System, Ribeirão Preto, SP, Brazil.

Correspondence: Edgard Eduard Engel. Hospital das Clínicas, Av. Bandeirantes, 3900, 11 andar, 14049-900 Ribeirão Preto, SP, Brazil. engel@fmrp.usp.br

Article received in 03/12/2015, approved in 05/07/2015

Acta Ortop Bras. 2015;23(4):197-201 
We believe that a cement with an elasticity modulus similar to cancellous bone and large interconnected pores would offer favorable conditions for bone remodeling. The mechanical strength of the cement must be sufficient to provide early support loading and prevention of fractures, but at the same time allowing the mechanical stimulus to occurs in order to promote bone neogenesis. ${ }^{7,8}$ Moreover, the presence of large interconnected pores must make room for this new bone formation and allow free movement of nutrients and osteoinductive components.

The objective of this study was to analyze the physical and mechanical characteristics of a PMMA based porous cement. Various concentrations of the effervescent components were tested to determine the best technique for the production of large interconnected pores and increase the elasticity of the cement making it similar to that of cancellous bone. It is expected that these characteristics improve osseointegration of the cement block and decrease the rates of complications related to solid PMMA.

\section{MATERIALS AND METHODS}

In all experiments we used medium viscosity PMMA cement and medium drying time (De Puy ${ }^{\circledR}$ SmartSet Endurance MV, Johnson \& Johnson ${ }^{\circledR}$, England).

To forty grams of powder polymer sodium bicarbonate and citric acid (weight ratio 1:1) were added in the amount defined by each group: G1 (10\% polymer by weight: $4 \mathrm{~g}$ sodium bicarbonate and $4 \mathrm{~g}$ citric acid), G2 (20\%), and G3 (30\%). (Table 1) Following the method of Boger et al. ${ }^{4}$ an homogeneous fluid was obtained by manual mixing the powder and the liquid component with a spatula in a stainless steel recipient at a stirring rate of about 100 strokes per min for 1 min. After 3 min, $5 \mathrm{ml}$ of distilled water were added and, after $1 \mathrm{~min}$ of stirring, the mixture was poured into cylindrical Teflon molds $(40 \mathrm{~mm}$ height, $20 \mathrm{~mm}$ diameter). After 48h, the samples were removed from the molds. The standard environmental conditions were also followed for acrylic bone cement described in the ASTM F451-86 and ISO 5833 standards. Three different PMMA components and effervescent additives were produced, resulting in three groups of samples with different porosities (G1, G2, and G3). (Figure 1) A group consisting of bovine cancellous bone samples (G4) and an additional group of solid PMMA cement without the effervescent components (G5) has been considered as control groups. Each group was composed of 14 samples. The project was exempted from the Ethics Committee approval for not using experimental animals. Fourteen cylindrical specimens (40 mm height, $20 \mathrm{~mm}$ diameter) were obtained from the removal of the metaphyseal region of the bovine proximal tibia with a trephine. The samples were sectioned in the longitudinal direction of the bone and then frozen at $-20^{\circ} \mathrm{C}$ to preserve their mechanical properties. Prior to the mechanical testing the samples were transferred to a refrigerator at $3^{\circ} \mathrm{C}$ for $12 \mathrm{~h}$, then exposed to room temperature for additional $2 \mathrm{~h}$.

The morphology of the samples was observed by scanning electron microscopy (SEM) (Model EVO MA10, Zeiss, Oberkochen, Germany) under low intensity vacuum, using 20 $\mathrm{kV}$ voltage. Micrographs with 60x and 100x magnifications were used to analyze the microstructure, micro and macro pores. For SEM observation, samples were cut in cross section and covered with gold using $40 \mathrm{~mA}$ current for 240s.
Table 1. Groups and composition of cement samples.

\begin{tabular}{c|c|c|c|c}
\hline Groups & Polymer (g) & Liquid (g) & $\mathrm{NaHCO}^{3}(\mathbf{g})$ & ${\mathrm{C} 6 \mathrm{H} 80^{7}}^{(g)}$ \\
\hline G1 & 40 & 18.88 & 4 & 4 \\
\hline G2 & 40 & 18.88 & 8 & 8 \\
\hline G3 & 40 & 18.88 & 12 & 12 \\
\hline G4 & Bovine bone & & & \\
\hline G5 & 40 & 18.88 & 0 & 0 \\
\hline
\end{tabular}

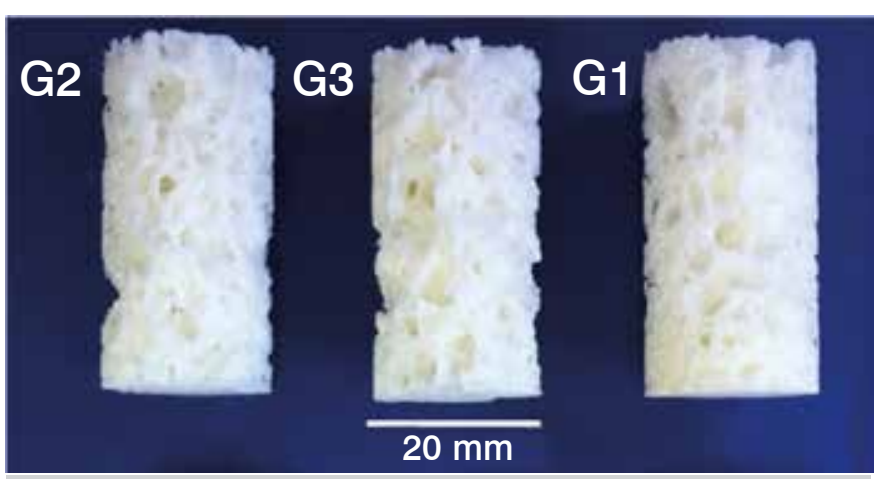

Figure 1. Samples of the three groups G1 (10\%), G2 (20\%) and G3 (30\%) of porous PMMA.

The height, diameter and weight of each sample were measured with a caliper and a digital precision scale. The apparent density of each sample was calculated according to equations (1) and (2):

$$
\begin{aligned}
& \rho=m / V(1) \\
& V=\pi \cdot r^{2} \cdot h(2)
\end{aligned}
$$

Each sample was submitted to computed microtomography $(\mu \mathrm{CT})$ using a high-resolution device (Microtomography Scanner model 1172, Bruker, Belgium). The pixel size was determined at $24.81 \mu \mathrm{m}$ under the following conditions: $49 \mathrm{kV}, 200$ $\mathrm{mA}$, and Al filter $0.5 \mathrm{~mm}$, and rotation step $0.4^{\circ}$ per slice. About 1,600 cuts per sample were generated. The reconstructed images were processed with CTAn ${ }^{\circledR}$ software (Bruker, Belgium). The customized processing was applied to the regions of interest (ROI) in the samples. The micromorphometric parameters, total porosity (Po (tot)) (\%), and total pore volume (Po.V (tot)), were calculated separately. The connectivity of the pores (Conn) and the connectivity density of the pores (Conn. Dn, $\mathrm{mm}^{3}$ ) were obtained by inverting the colors protocol.

The mechanical properties of the samples were obtained by compression tests in accordance with ISO standard 5833 specifications. The only change was the expansion of the samples due to their cancellous structure. For each group, 14 samples were tested. The universal testing machine, Instron 8872 (Instron, Norwood, MA) was used with a displacement rate of $20 \mathrm{~mm} \cdot \mathrm{min}^{-1}$. The forces were measured at $5 \mathrm{kN}$ load cell for porous cement samples and $25 \mathrm{kN}$ cell for solid cement samples. The deformations were processed with Complete Bluehill 2 Software Suite (Instron, Norwood, MA, USA).

Statistical analysis was performed comparing all groups with the Kruskal-Wallis test and Dunn post-test using the PROC MEANS procedure of $S A S^{\circledR} 9.2$ software (SAS Institute Inc., Cary, USA). 


\section{RESULTS}

The direct visual observation revealed a wide variation in the pore sizes distributed unevenly throughout the samples extension. However, none of the specimens was rejected for being considered damaged.

In all experimental groups (G1-G3), SEM confirmed the random pore distribution throughout the sample. Extensive areas of condensed cement were identified. Confined small pores could be found inside the thicker cement beams. The pore size showed a wide range from $50 \mu \mathrm{m}$ to $3 \mathrm{~mm}$ in samples of experimental groups, whereas the pore size was more homogeneous in samples of bovine cancellous bone. The presence of larger pores was more frequent in G3 and less frequent in G1, but the pore size did not vary between the groups. SEM analysis also suggested that the interconnection occurs through large holes, whereas in the cancellous bone openings were smaller. (Figure 2) The measured apparent density was $0.40 \pm 0.08 \mathrm{~g}_{\mathrm{cm}} \mathrm{cm}^{-3}$ for G1; $0.33 \pm 0.04 \mathrm{~g} . \mathrm{cm}^{-3}$ for G2, and $0.41 \pm 0.04 \mathrm{~g}_{\mathrm{cm}} \mathrm{cm}^{-3}$ for G3. The density of the cancellous bone of the proximal bovine tibia ranged from

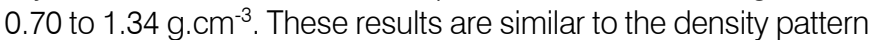
of human trabecular bone ranging from 0.28 to $1.8 \mathrm{~g} . \mathrm{cm}^{-3} .14$

The total porosity measured by $\mu \mathrm{CT}$ was $62.75 \pm 2.47 \%$ for G1; $75.75 \pm 1.56 \%$ for G2; and $72.34 \pm 1.39 \%$ for G3. There was a statistically significant difference between G1 and G2 $(p=0.03)$. Regarding total pore volume, average values of $6918.6 \pm 287.7 \mathrm{~mm}^{3}$ for G1; $8316.8 \pm 171.3 \mathrm{~mm}^{3}$ for G2; and $7938.8 \pm 153.6 \mathrm{~mm}^{3}$ for $\mathrm{G} 3$ were found. A significant difference between $\mathrm{G} 1$ and $\mathrm{G} 2(\mathrm{p}=0.03)$ was observed. The pores interconnectivity analysis showed similar results with significantly higher values for G3. (Table 2)

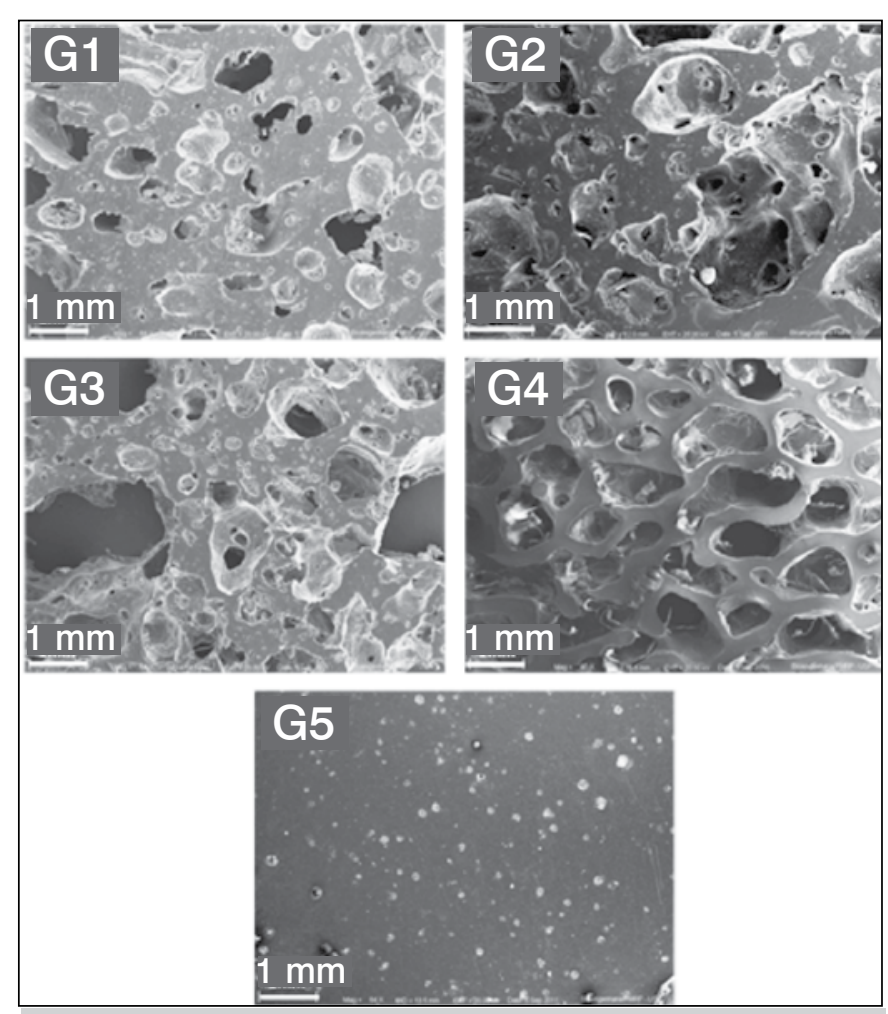

Figure 2. Scanning electron microscopy of samples G1, G2, G3 (porous cement), G4 (bovine cancellous bone) and G5 (solid cement). Magnification 60x.
The resistance and Young's modulus of solid cement were 12 and 6.5 times higher than the cancellous bone, respectively. There were no significant differences in the resistance and the elasticity modulus between the samples of porous cement and the bovine cancellous bone samples, except for the resistance values between G2 (20\%) and G4 (bovine bone) ( $p=0.01$ ). The elasticity modulus and the resistance of porous cement samples were 33 to $55 \%$, and 15 to $57 \%$ smaller than those of bovine cancellous bone, respectively. (Table 3)

Considering the mechanical properties of the porous cement, our results suggest that there is no difference between the cement with effervescent components concentrations from $10 \%$ to $30 \%$.

Table 2. Physical properties ( $\mu$ CT analysis)

\begin{tabular}{c|c|c|c|c|c|c|c|c}
\hline Groups & \multicolumn{2}{|c|}{$\begin{array}{c}\text { Total porosity } \\
\text { total (Po(tot)) \% }\end{array}$} & \multicolumn{2}{|c|}{$\begin{array}{c}\text { Total volume } \\
\text { of pores } \\
\text { (Po.V(tot)) mm }\end{array}$} & \multicolumn{2}{|c|}{$\begin{array}{c}\text { Density of pores } \\
\text { connectivity } \\
\text { (Conn.Dn) mm }\end{array}$} & \multicolumn{2}{c|}{$\begin{array}{c}\text { Connectivity of } \\
\text { pores (Conn) }\end{array}$} \\
\hline G1 (10\%) & 62.750 & \pm 2.475 & 6918.6 & \pm 287.7 & 18.522 & \pm 3.481 & 204158.7 & \pm 37888.7 \\
\hline G2 (20\%) & 75.757 & \pm 1.565 & 8316.8 & \pm 171.3 & 11.300 & \pm 1.277 & 124050.0 & \pm 13936.3 \\
\hline G3 (30\%) & 72.344 & \pm 1.399 & 7938.8 & \pm 153.6 & 26.664 & \pm 7.509 & 292596.3 & \pm 82396.0 \\
\hline
\end{tabular}

Data are presented as mean \pm standard deviation (St. Dev.). Values measured show statistical difference. a: $G 2>G 1(p<0.05) ; b: G 1>G 2, G 3>G 2(p<0.05)$

Table 3. Mechanical properties (Young's modulus and drained tension) by the compression test as Mean (St. Dev.), $n=14$.

\begin{tabular}{c|c|c}
\hline Groups & Young's modulus (MPa) & Drained tension (MPa) \\
\hline G1 (10\%) & $238.88(78.71)$ & $4.43(1.75)$ \\
\hline G2 (20\%) & $158.76(40.51)$ & $2.21(0.74)$ \\
\hline G3 (30\%) & $179.59(43.57)$ & $2.53(0.45)$ \\
\hline G4 (bone) & $359.32(163.22)$ & $5.24(2.47)^{\mathrm{b}}$ \\
\hline G5 (0\%) & $2342.26(123.49)^{\mathrm{a}}$ & $66.96(5.6)^{\mathrm{a}}$ \\
\hline \multicolumn{2}{c|}{ Values measured show statistical difference a) G5 $>$ G1. G2 $\mathrm{G}$ G3 (p $<0.01)$. b. G4> G2 $(\mathrm{p}<0.01)$}
\end{tabular}

\section{DISCUSSION}

A PMMA mixture containing 20 to $30 \%$ of sodium bicarbonate and citric acid produces a porous concrete with compressive resistance and elasticity equivalent to those of cancellous bone. Moreover, it presents interconnected macropores. (Figures 3 and 4)

The results of the cancellous bovine bone control group were considered adequate, since the value of Young's modulus (352 $\pm 145 \mathrm{MPa}$ ) was similar to the values obtained by Banse et al. ${ }^{14}$ (359.32 \pm 163.22 MPa) from 62 human vertebral male and female bodies. The small differences between the elasticity limits of the studies can be explained by the variability between the bones and the loads they support.

Solid cement is widely used as a cancellous bone substitute and it is not uncommon the formation of a narrow layer of fibrous tissue surrounding the concrete block. When performing curettage of benign tumors adjacent to the subchondral bone in the periarticular area, this fibrous tissue can decrease the load bearing capacity, resulting in an uneven surface and insidious onset of arthrosis. ${ }^{15}$ It is believed that the main causes which lead to the formation of this fibrous tissue are the overheating during cement drying, the confinement of the bone segment by the cement block interrupting the blood supply, and the discrepancy of elasticity between the cancellous bone and the 

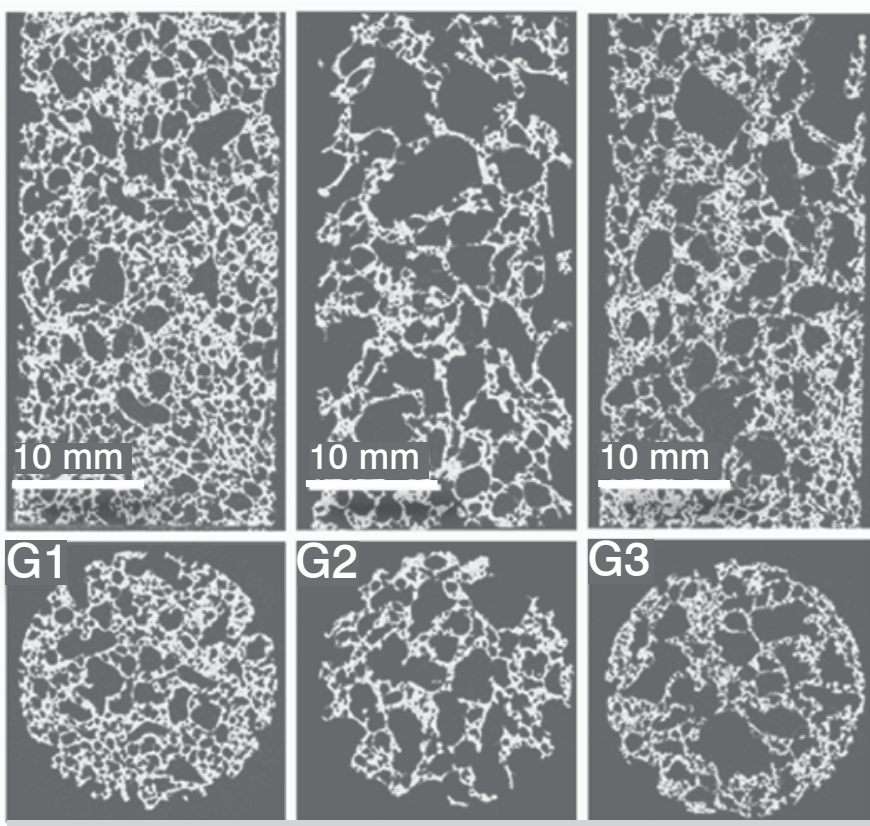

Figure 3. 2D Reconstruction ( $\mu \mathrm{CT}$ ) of groups $\mathrm{G} 1, \mathrm{G} 2$ and $\mathrm{G} 3$.

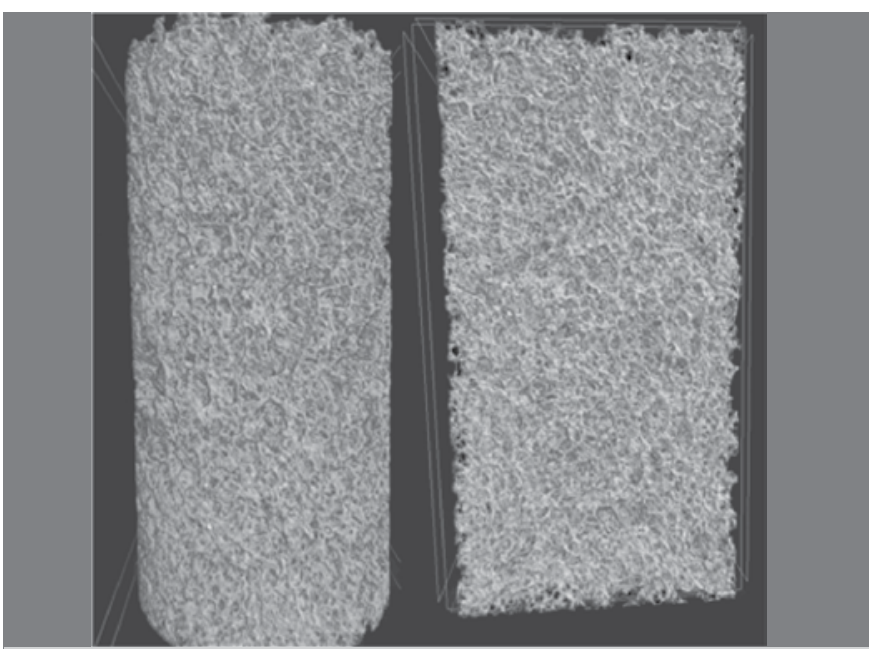

Figure 4. 3D Reconstruction ( $\mu \mathrm{CT}$ ) of a G2 group sample (20\%).

cement. ${ }^{16}$ In theory, the porous cement could inhibit the formation of this fibrous tissue and promote osseointegration. It achieves maximum temperatures lower than the solid cement during drying, thus, decreasing the risk of necrosis. ${ }^{17}$ The interconnected pores could allow the fluid to circulate freely, thus reducing the nutritional deficiency of neighboring regions. ${ }^{18}$ Furthermore, it can allow invasion of bone tissue within the macropores accompanied by vascular neogenesis. Although this cement architecture reduces its final resistance, its elasticity is increased, equating it to the cancellous bone and eliminating shear stresses at the interface.

The term "macropores" refers to pore size ranging from about $100 \mu \mathrm{m}$ to $1 \mathrm{~mm} .{ }^{19}$ Using an experimental model in rats, Tsuruga et al..$^{20}$ demonstrated that pores from 300 to $400 \mu \mathrm{m}$ are ideal for osteoblasts invasion. Other studies have determined that pores larger than 30 to $50 \mu \mathrm{m}$ are sufficient for cellular invasion. ${ }^{21}$ Miño-Fariña et al. ${ }^{6}$ stated that metaphyseal defects in rabbit femurs filled with a $\alpha$-TCP ( $\alpha$-tricalcium phosphate) based porous cement had good peripheral osseointegration, but poor bone invasion in the center. The cement pores presented in this study measured $100-300 \mu \mathrm{m}$.

In studies on porous substrates for tissue engineering, the pore size is critical for osteoconductive properties and sizes between $100 \mu \mathrm{m}$ and $400 \mu \mathrm{m}$ seem most effective. 6,20 However, this statement is applicable to small dimensions and only considers peripheral osseointegration. In large defects a bone massive invasion is required to recover vitality and mechanical strength. Bone remodeling certainly behaves differently in large bone defects. The interconnection of pores allows free diffusion of nutrients and osteoinductive substances. In fact, some authors suggest that the degree of interconnectivity is more important than the pore size.22

A different hypothesis is proposed in this study. Instead of the smaller pores invaded by osteoblasts, we believe that larger pores, up to $3 \mathrm{~mm}$, can be invaded by solid bone, as in the case of defects not filled by substitutes. Hirn et al. ${ }^{13}$ demonstrated the natural tendency of bone in filling cavities to regain its loadbearing capacity, even in large defects. A porous cement must not interfere with this tendency and, furthermore, must provide some mechanical stability preventing fractures during the remodeling period. It is not yet established whether using porous cement effectively improves osseointegration and allows invasion of newly formed bone. In vivo studies are required to confirm this hypothesis in conditions of large bone defects. When a solid cement is used as a cancellous bone substitute, a difference in the elasticity of materials normally causes bone resorption and sclerosis along the tension lines. ${ }^{4}$ This difference causes unwanted motion at the interface and prevent osseointegration by interfering with the natural tendency of bone invasion. Moreover, for the same reason, solid cement takes much of the load-bearing reducing the stimulus to bone remodeling in its surroundings. ${ }^{2,12}$ Additional studies are needed to clarify the influence of cement resistance and stiffness in osseointegration.

The random and irregular distribution of pores and the wide variation of their size in the study samples should be considered disadvantageous. However, these characteristics do not substantially affect the standard deviation of the mechanical parameters of porous cement samples which were even lower than that of control samples of bovine cancellous bone. Thus, with regard to the physical aspects, the porous cement has characteristics similar to those of biological tissues.

Boger et al. ${ }^{4}$ used a sodium hyaluronate solution as porogenic component to produce a bone cement with adequate porosity and Young's modulus value similar to cancellous bone's. No detail was provided on its interconnectivity. Anh et al. ${ }^{17}$ mixed blood in cement samples, but the reduced Young's modulus has not reached the level of the cancellous bone (545.6 MPa). He et al..$^{23}$ produced a porous cement by mixing PMMA with NovaBone ${ }^{\circledR}$ and chitosan. The mechanical properties of the cement were similar to those of the cancellous bone. The cement also showed osteoinduction potential. However, this material has to be prepared prior to surgery and its interconnectivity has not been discussed.

Hesaraki et al. ${ }^{5}$ used the same porogenic agents used in this study, but they mixed calcium phosphate cement (CFC). The 
material contained interconnected macropores, but its production technique is not feasible in the operating room because it must be heated at $1,500^{\circ} \mathrm{C}$ for $6 \mathrm{~h}$.

Lopez-Heredia et al. ${ }^{24}$ used PMMA added to calcium phosphate and sodium carboxymethylcellulose (CMC) as porogenic components. This cement had interconnected $230 \mu \mathrm{m}$ pores in average and a Young's modulus of $220 \mathrm{MPa}$, but its production takes 5 to $6 \mathrm{~h}$.

The porous cement appears to be a promising alternative for filling bone defects in the treatment of benign bone tumors. Large bone defects must be replaced in a favorable biological environment to improve the survival of the subchondral bone, induce osseointegration and prevent fractures. The biological behavior and safety of porous cements should be further investigated before clinical use.

\section{CONCLUSION}

Sodium bicarbonate and citric acid can be used as porogenic components for producing a porous PMMA-based cement, which can be molded in the operating room and it is easily reproducible. The bone graft substitute has large interconnected pores and Young's modulus values similar to that of cancellous bone. It is expected that these favorable characteristics stimulate bone remodeling at the same time they prevent fractures in the treatment of large metaphyseal bone defects.

\section{ACKNOWLEDGEMENTS}

The authors are deeply indebted to FAPESP (Fundação de Amparo à Pesquisa do Estado de São Paulo) for the support given to this study (Process 2010/08315-2).

\section{REFERENCES}

1. Kundu ZS, Gupta V, Sangwan SS, Rana P. Curettage of benign bone tumors and tumor like lesions: a retrospective analysis. 2013;47(3):295-301.

2. Wada T, Kaya M, Nagoya S, Kawaguchi S, Isu K, Yamashita T, et al. Complications associated with bone cementing for the treatment of giant cell tumors of bone. J Orthop Sci. 2002;7(2):194-8.

3. Belkoff SM, Molloy S. Temperature measurement during polymerization of polymethylmethacrylate cement used for vertebroplasty. Spine (Phila Pa 1976). 2003; 28(14):1555-9.

4. Boger A, Bohner M, Heini P, Verrier S, Schneider E. Properties of an injectable low modulus PMMA bone cement for osteoporotic bone. J Biomed Mater Res B Appl Biomater. 2008; 86(2):474-82.

5. Hesaraki S, Moztarzadeh F, Sharifi D. Formation of interconnected macropores in apatitic calcium phosphate bone cement with the use of an effervescent additive. J Biomed Mater Res A. 2007;83(1):80-7.

6. Miño-Fariña N, Muñoz-Guzón F, López-Peña M, Ginebra MP, Del Valle-Fresno $S$, Ayala D, et al. Quantitative analysis of the resorption and osteoconduction of a macroporous calcium phosphate bone cement for the repair of a critical size defect in the femoral condyle. Vet J. 2009;179(2):264-72.

7. Klijn RJ, van den Beucken JJ, Félix Lanao RP, Veldhuis G, Leeuwenburgh SC Wolke JG, et al. Three different strategies to obtain porous calcium phosphate cements: comparison of performance in a rat skull bone augmentation model. Tissue Eng Part A. $2012 ; 18(11-12): 1171-82$.

8. Beck S, Boger A. Evaluation of the particle release of porous PMMA cements during curing. Acta Biomater. 2009;5(7):2503-7.

9. Xu H, Burguera E, Carey L. Strong, macroporous, and in situ-setting calcium phosphate cement-layered structures. Biomaterials. 2007;28(26):3786-96.

10. Del Real RP, Ooms E, Wolke JG, Vallet-Regí M, Jansen JA. In vivo bone response to porous calcium phosphate cement. J Biomed Mater Res A. 2003;65(1):30-6.

11. Hesaraki S, Zamanian A, Moztarzadeh F. The influence of the acidic component of the gas-foaming porogen used in preparing an injectable porous calcium phosphate cement on its properties: acetic acid versus citric acid. J Biomed Mater Res B Appl Biomater. 2008;86(1):208-16

12. Huiskes $R$. If bone is the answer, then what is the question? J Anat. 2000; 197:145-56.

13. Hirn M, de Silva U, Sidharthan S, Grimer RJ, Abudu A, Tillman RM, et al. Bone defects following curettage do not necessarily need augmentation. Acta

Orthop. 2009;80(1):4-8.

14. Banse X, Sims TJ, Bailey AJ. Mechanical properties of adult vertebral cancellous bone: correlation with collagen intermolecular cross-links. J Bone Miner Res. 2002;17(9):1621-8.

15. Welch RD, Berry BH, Crawford K, Zhang H, Zobitz M, Bronson D, et al. Subchondral defects in caprine femora augmented with in situ setting hydroxyapatite cement, polymethylmethacrylate, or autogenous bone graft: biomechanical and histomorphological analysis after two-years. J Orthop Res. 2002;20(3):464-72.

16. Mitzner E, Albertus P, Maria H, Mueller C, Berlin D-. Material properties and in vitro biocompatibility of a newly developed bone cement. Mater Res. 2009;12(4):447-54.

17. Ahn DK, Lee S, Choi DJ, Park SY, Woo DG, Kim CH, et al. Mechanical properties of blood-mixed polymethylmetacrylate in percutaneous vertebroplasty. Asian Spine J. 2009;3(2):45-52.

18. Almirall A, Larrecq G, Delgado JA, Martínez S, Planell JA, Ginebra MP. Fabrication of low temperature macroporous hydroxyapatite scaffolds by foaming and hydrolysis of an alpha-TCP paste. Biomaterials. 2004;25(17):3671-80.

19. Xu HH, Takagi S, Quinn JB, Chow LC. Fast-setting calcium phosphate scaffolds with tailored macropore formation rates for bone regeneration. J Biomed Mater Res A. 2004;68(4):725-34.

20. Tsuruga E, Takita $H$, Itoh $H$, Wakisaka Y, Kuboki Y. Pore size of porous hydroxyapatite as the cell-substratum controls BMP-induced osteogenesis. J Biochem. 1997;121(2):317-24.

21. Van Lenthe $\mathrm{GH}$, Hagenmüller $\mathrm{H}$, Bohner M, Hollister SJ, Meinel L, Müller R. Nondestructive micro-computed tomography for biological imaging and quantification of scaffold-bone interaction in vivo. Biomaterials. 2007;28(15):2479-90.

22. Hing KA, Best SM, Bonfield W. Characterization of porous hydroxyapatite. J Mater Sci Mater Med. 1999;10(3):135-45.

23. He Q, Chen H, Huang L, Dong J, Guo D, Mao M, et al. Porous surface modified bioactive bone cement for enhanced bone bonding. PLoS One . 2012;7(8):e42525.

24. Lopez-Heredia MA, Sa Y, Salmon P, de Wijn JR, Wolke JGC, Jansen JA. Bulk properties and bioactivity assessment of porous polymethylmethacrylate cement loaded with calcium phosphates under simulated physiological conditions. Acta Biomater. 2012;8(8):3120-7. 